\title{
A simple method for the deposition of nanostructured tellurium synthesized in ammonia solution
}

\author{
C. D. Gutiérrez-Lazos ${ }^{1}$ (1) F. Solís-Pomar ${ }^{1}$ - M. F. Meléndrez ${ }^{2}$ A. M. Espinoza-Rivas ${ }^{3}$ • \\ M. A. Pérez-Guzmán ${ }^{4} \cdot$ R. Ortega-Amaya ${ }^{3} \cdot$ M. Ortega-López ${ }^{3}$ - E. Pérez-Tijerina ${ }^{1}$
}

Received: 17 November 2015/Accepted: 4 February 2016/Published online: 15 February 2016

(c) The Author(s) 2016. This article is published with open access at Springerlink.com

\begin{abstract}
In this work, we report a highly adherent, and uniform deposition of nanostructured tellurium. The deposition of the nanostructured tellurium was realized by the dripping of a modified solution of NaHTe based on the dissolution of $\mathrm{NaBH}_{4}$ and tellurium powder in an aqueous solution of $\mathrm{NH}_{4} \mathrm{OH}$. This method allowed the relatively simple manipulation of tellurium nanostructures under laboratory ambient, without requiring the use of organic stabilizers. Transmission electron microscopy (TEM) was realized on a powder sample obtained by the reaction between $\mathrm{H}_{2} \mathrm{Te}$ and aqueous solution of $\mathrm{NH}_{4} \mathrm{OH}$. TEM analysis indicated that tellurium nanorods and Y-type nanostructures are grown from tellurium nanoparticles, such as in a hydrothermal system. Then, the nanoparticles
\end{abstract}

C. D. Gutiérrez-Lazos

claudio.gutierrezl@uanl.edu.mx

1 Centro de Investigación en Ciencias Físico Matemáticas, Facultad de Ciencias Físico Matemáticas, Universidad Autónoma de Nuevo León, Av. Universidad s/n. Ciudad Universitaria, 66451 San Nicolás de los Garza, N.L., Mexico

2 Advanced Nanocomposites Research Group (GINA), Hybrid Materials Laboratory (HML), Department of Materials Engineering (DIMAT), Faculty of Engineering, University of Concepcion, 270 Edmundo Larenas, Box 160-C, 4070409 Concepción, Chile

3 Sección de Electrónica del Estado Sólido, Centro de Investigación y de Estudios Avanzados del Instituto Politécnico Nacional, Av. Instituto Politécnico Nacional 2508, Col. San Pedro Zacatenco, 07360 Mexico, D.F., Mexico

4 Programa de Doctorado en Nanociencias y Nanotecnología, Centro de Investigación y de Estudios Avanzados del Instituto Politécnico Nacional, Av. Instituto Politécnico Nacional 2508, Col. San Pedro Zacatenco, 07360 Mexico, D.F., Mexico serve as seeds for the growth of more extended tellurium nanostructures. Electron diffraction and X-ray diffraction analysis showed that depositions have the hexagonal structure of tellurium highly oriented on (101) direction.

Keywords Tellurium $\cdot$ Nanostructures $\cdot$ Transmission electron microscopy $\cdot \mathrm{X}$-ray diffraction

\section{Introduction}

Tellurium is a material of special interest in technology due to its special physical and chemical properties. Tellurium exhibits catalytic activity (Fujiwara et al. 1992), photoconductivity (Ufimtsev et al. 1997) and interesting piezoelectric and thermoelectric properties (Gerlach and Grosse 1979; Cooper 1974). It has been demonstrated by solution synthesis, that tellurium precipitates in nearly spherical nanoparticles whose crystal structure is trigonal. These nanoparticles have the capability to grow nanowires, nanorods and nanobelts (with hexagonal crystalline phase) in a vapor phase reactor, where tellurium nanoparticles serve as seeds (Furuta et al. 1975). On the other hand, it is widely known that the preparation of a NaHTe solution, where elemental tellurium is used as precursor, requires a strong reduction condition supported by an inert atmosphere due that tellurium is tetra-positive in valence and is insoluble. Additionally, telluride ion is highly reactive with oxygen (Gautam and Rao 2004), this reactivity promotes the formation of tellurates with the exposition of the sample to the laboratory environment. In this context, sodium borohydride has proved to be a strong reducer and partially dissolves the tellurium. Otherwise, the NaHTe reaction produces sodium borates, considered as contaminants; however, these borates are easily removed by 
decanting. To obtain a tellurium deposition by chemical methods, it is necessary solve the above problems.

In the present report, we found that the preparation of NaHTe complex under basic conditions is an excellent precursor for adherent, uniform and free-borates tellurium deposition. This synthesis has the advantage of be realized completely under ambient conditions. Finally, we also found that the reaction between $\mathrm{H}_{2} \mathrm{Te}$ gas (obtained by the decomposition of NaHTe by the $\mathrm{H}_{2} \mathrm{SO}_{4}$ injection) and $\mathrm{NH}_{4} \mathrm{OH}$ aqueous solution triggers the formation of tellurium nanostructures such as nanorods and "Y" structures, which are obtained only by hydrothermal synthesis and using a surfactant.

\section{Experimental}

\section{Materials}

Tellurium powder (-200 mesh, $99.8 \%$ Aldrich); sodium borohydride $\left(\mathrm{NaBH}_{4}\right.$, mesh, $99.8 \%$ Aldrich), ammonium hydroxide (35\%, J.T. Baker).

\section{Synthesis of NaHTe in ammonia solution (NaHTe: $\mathrm{NH}_{3}$ )}

The preparation of sodium hydrogen telluride in ammonia solution (NaHTe: $\mathrm{NH}_{3}$ ) was based on a method reported by $\mathrm{Gu}$ et al. (2008), where $204.2 \mathrm{mg}$ (1.6 mmol) of tellurium powder and $157.8 \mathrm{mg}(4.2 \mathrm{mmol})$ of $\mathrm{NaBH}_{4}$ were loaded in a $50 \mathrm{~mL}$ Erlenmeyer flask. Afterwards, $20 \mathrm{~mL}$ of $\mathrm{NH}_{4}$ $\mathrm{OH}(164 \mathrm{mmol})$ solution was added and the mixture was heated up to $80{ }^{\circ} \mathrm{C}$ under $\mathrm{N}_{2}$ atmosphere during $15 \mathrm{~min}$ of constant stirring. Tellurium nanostructured thin films were deposited by dripping of NaHTe: $\mathrm{NH}_{3}$ on glass substrate under laboratory conditions and the depositions were analyzed by X-ray diffraction.

\section{Synthesis of NaHTe: $\mathrm{NH}_{3}$ using $\mathrm{H}_{2} \mathrm{Te}$ as telluride ion precursor}

According to the reaction presented by Gautam and Rao (2004) and Zheng et al. (2004), the synthesis of NaHTe produces a secondary phase of sodium borate $\left(\mathrm{Na}_{2} \mathrm{~B}_{4} \mathrm{O}_{7}\right)$ consisting of a whitish sediment. As an effort to reduce the secondary phases such as sodium borate and tellurates during the synthesis, samples of $\mathrm{NaHTe}: \mathrm{NH}_{3}$ were prepared by employing a method proposed by Bao et al. (2004). In $20 \mathrm{~mL}$ of an aqueous solution of NaHTe, $2 \mathrm{~mL}$ (36.7 mmol) of sulfuric acid were injected to obtain $\mathrm{H}_{2} \mathrm{Te}$. Hydrogen telluride was transferred to a solution of $\mathrm{NH}_{4} \mathrm{OH}$ ( $20 \mathrm{~mL}, 0.1 \mathrm{M}$ ) through a bubbler by using $\mathrm{N}_{2}$ flux. The solution acquired the characteristic purple tonality of
NaHTe solution; nevertheless, 2 min later, solution loses stability and was turned transparent, and tellurium particles were flocculated on the vessel bottom. The flocculate was analyzed by transmission electron microscopy (TEM).

\section{Characterization}

Morphology and size of tellurium nanostructures were analyzed by TEM using a JEOL 2010 microscope, operated with $100,000 \times$ and $400,000 \times$ magnification. The samples were dropped on 300 mesh Lacey carbon grid, dried under laboratory conditions, and then introduced to the microscope vacuum chamber. X-ray diffraction (XRD) measurements were done on deposited NaHTe: $\mathrm{NH}_{3}$ in a Phillips x́Pert diffractometer at normal incidence, using monochromatic $\mathrm{Cu} \mathrm{K}_{\alpha}$ radiation.

\section{Results and discussion}

\section{TEM analysis}

Although the NaHTe: $\mathrm{NH}_{3}$ samples were not stable, the collected products allowed us to observe a variety of crystalline structures such as rounded tellurium nanoparticles (Fig. 1) and nanostructures such as nanorods (Fig. 2), Y-like nanostructures (Fig. 3), and bigger crystallites produced by the subsequent aggregation of these nanostructures (inset of Fig. 3).

The mean diameter measured for the rounded nanoparticles displayed in Fig. 1 was $10 \mathrm{~nm}$. The nanorods showed in Fig. 2 have a mean width of $15 \mathrm{~nm}$, practically without appreciable variation and their length varies from 60 to $158 \mathrm{~nm}$. Gautam and Rao (2004)

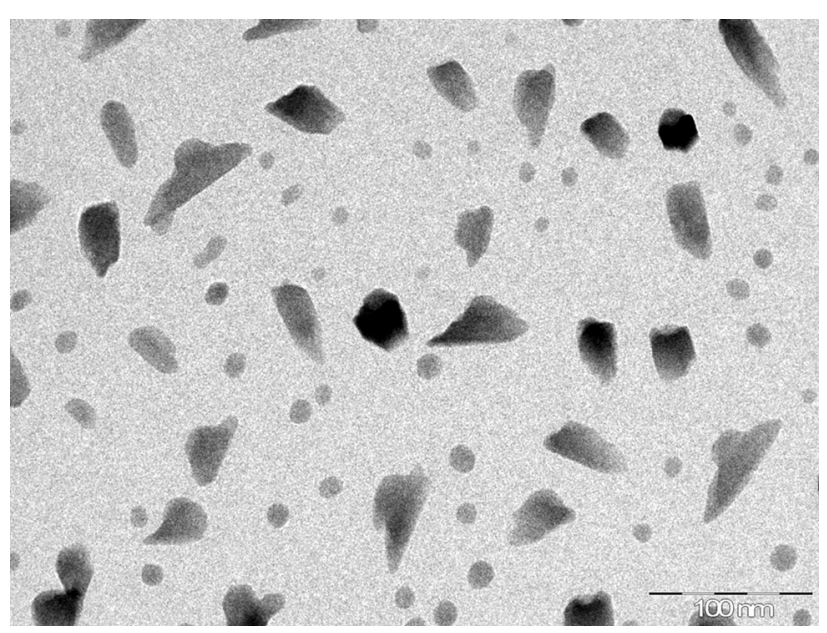

Fig. 1 TEM micrography of a powder obtained from NaHTe: $\mathrm{NH}_{3}$ sample using $\mathrm{H}_{2} \mathrm{Te}$ as telluride ion precursor 


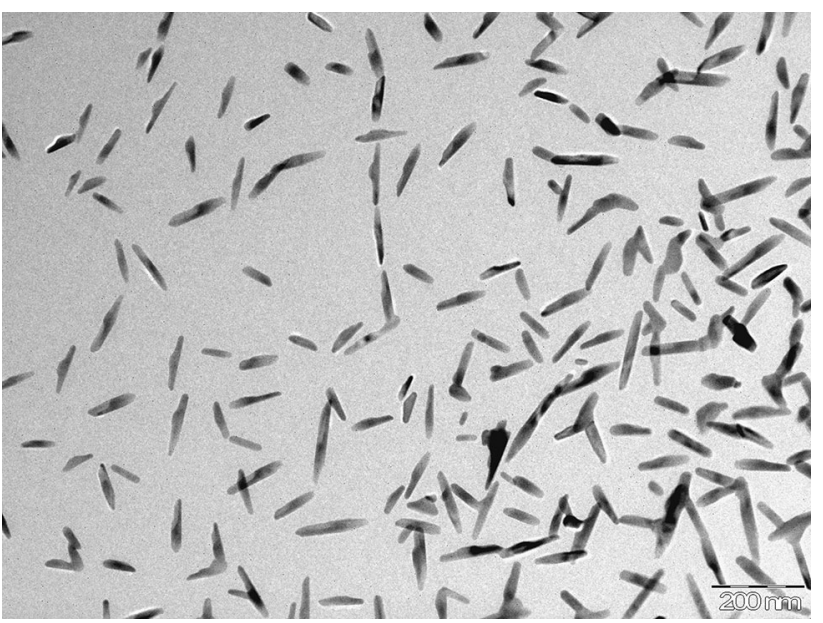

Fig. 2 TEM micrography of nanorods observed in a powder obtained from $\mathrm{NaHTe}: \mathrm{NH}_{3}$ sample using $\mathrm{H}_{2} \mathrm{Te}$ as telluride ion precursor

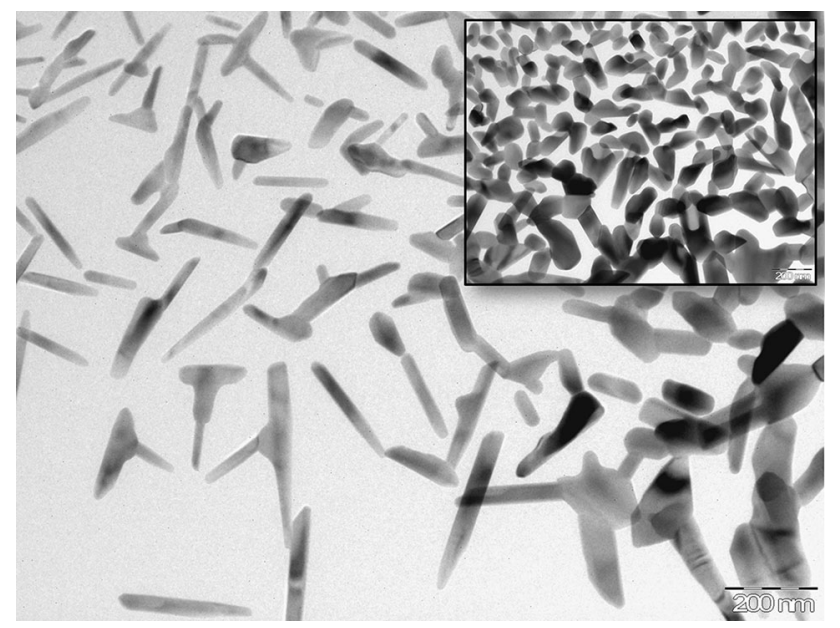

Fig. 3 TEM micrography of Y-type nanostructures observed in a powder obtained from $\mathrm{NaHTe}: \mathrm{NH}_{3}$ sample using $\mathrm{H}_{2} \mathrm{Te}$ as telluride ion precursor. The inset exhibits higher crystallites formed by the nanostructure aggregation

observed the formation of these nanostructures through a hydrothermal synthesis of NaHTe, employing sodium dodecylbenzenesulfonate as surfactant, and as oxidation inhibitor. In this work no surfactant was used, since our intention was prepared a tellurium deposition; nevertheless, the simple reaction between $\mathrm{H}_{2} \mathrm{Te}$ and ammonia solution has produced tellurium nanoparticles that have operated like seeds for the growth of nanorods (Fig. 4), and the formation of Y-like nanostructures (Furuta et al. 1975). These nanostructures also may be formed by the aggregation of nanorods as shown in the micrograph of Fig. 2. Electron diffraction analysis was realized on the nanostructure showed on the micrography of Fig. 4 and the result was the hexagonal structure of tellurium (Rabadanov et al. 2000).

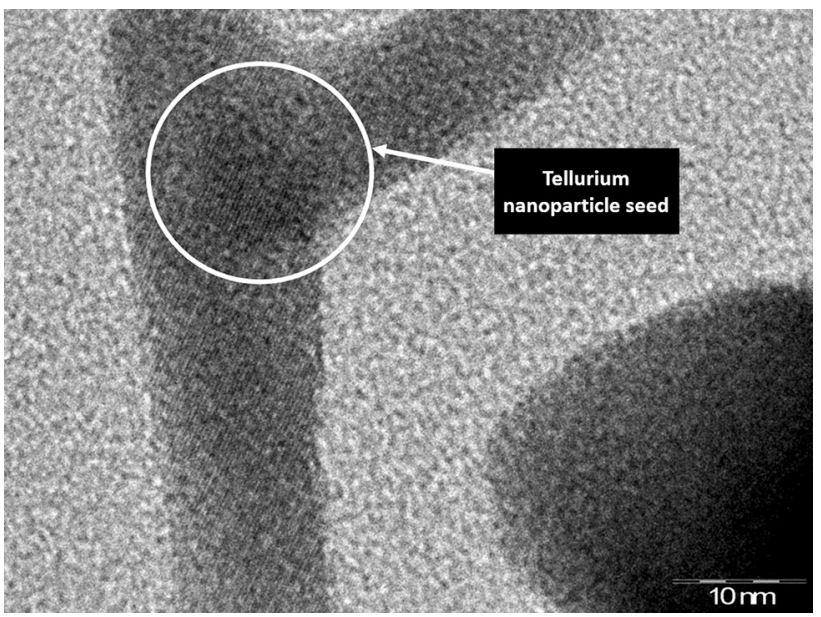

Fig. 4 TEM micrography of Y-type nanostructure observed in a powder obtained from NaHTe: $\mathrm{NH}_{3}$ sample using $\mathrm{H}_{2} \mathrm{Te}$ as telluride ion precursor. The micrography exhibits a tellurium nanoparticle that serves as seed for the growth of a "Y" structure

\section{X-ray diffraction analysis}

The first test looking for tellurium deposition was through the preparation of a colloidal solution with characteristics similar to an ink by the flocculation of tellurium nanoparticles in a NaHTe solution. Initially, we extracted the solid phase, including the insoluble whitish sediment on the flask bottom and further analysis by X-ray diffraction, indicated that this sediment is composed of several phases of sodium borate, such as reported by Gautam and Rao (2004) and is shown in Fig. 5. These phases represent a pollution source for the deposition and is the predominant phase in the $\mathrm{X}$-ray diffraction pattern showed in Fig. 5.

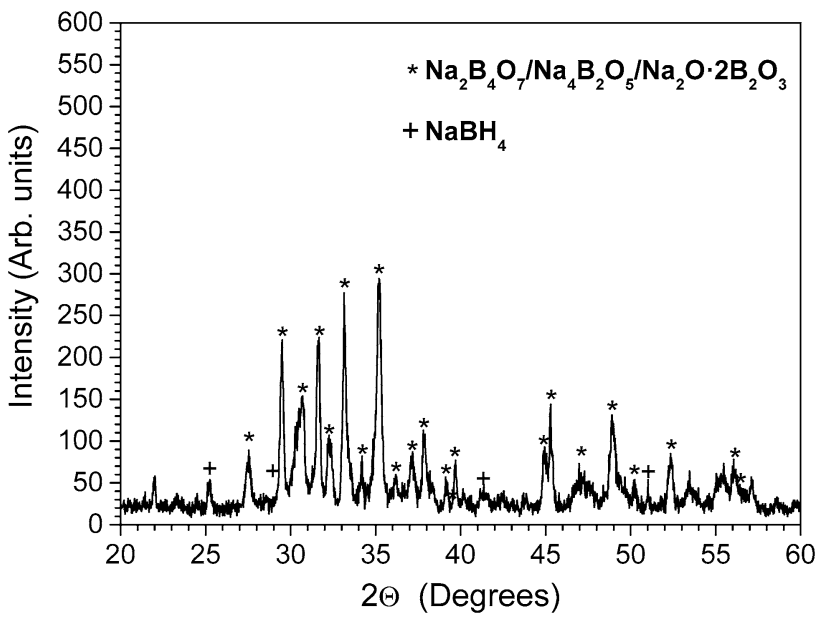

Fig. 5 X-ray diffraction pattern of a powder sample obtained by the flocculation of solid phase of a NaHTe solution including the whitish sediment on bottom flask, secondary product of NaHTe synthesis

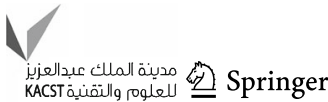




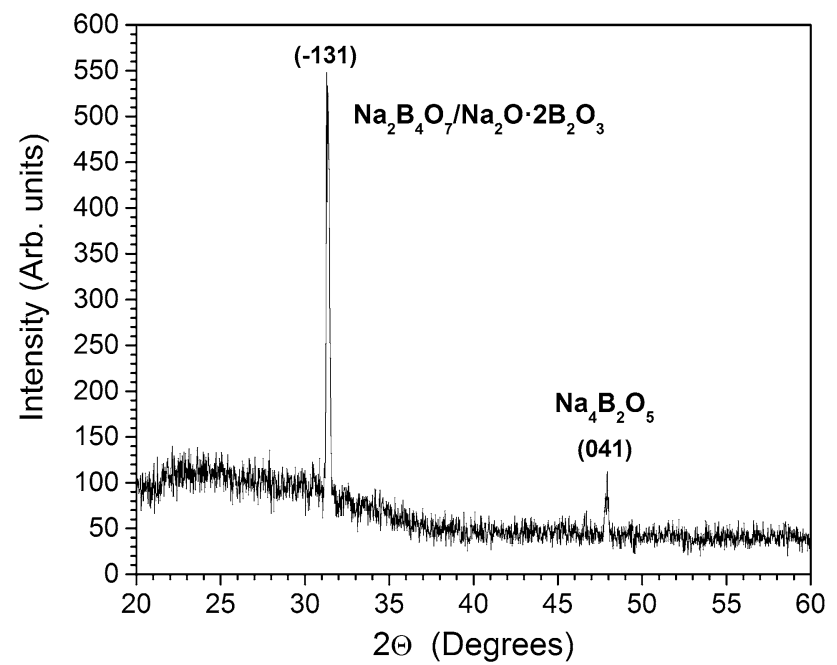

Fig. 6 X-ray diffraction pattern of a powder sample obtained by the flocculation of solid phase of a NaHTe solution without the whitish sediment on bottom flask

Figure 6 corresponds to X-ray diffraction pattern for a sample prepared by the flocculation of solid phase from a NaHTe solution, with no borates on the flask bottom and under laboratory conditions. In spite of the number of diffraction peaks for the different phases of sodium borate were reduced, we did not observe any diffraction peak generated by tellurium or a tellurium based compound, such as oxides and tellurates given the strong reactivity between the ion telluride and oxygen.

The NaHTe: $\mathrm{NH}_{3}$ solution resulted with a dark-purple tonality and with a higher viscosity and stability compared with a standard NaHTe solution. Tellurium deposition was significantly easier, because inert atmosphere, flocculation and cleaning of solid phase were not required. A simple synthesis in ammonium hydroxide solution allowed to produce a solution with the characteristics of an ink and the volatility of ammonia also allowed the rapid evaporation of aqueous media, resulting the nanostructured tellurium deposition with high adherence and uniformity.

Despite the simplicity of this synthesis, we must note that sodium borates phases were not removed once tellurium powder and sodium borohydride were dissolved in ammonia solution, due to forming a viscous and darker solution. For this reason, we try to gasify an aqueous ammonium hydroxide solution with $\mathrm{H}_{2} \mathrm{Te}$, but the product proved to be unstable.

The diffraction pattern of a tellurium nanostructure deposition is displayed in Fig. 7, it is clear that we have obtained a tellurium thin film highly starting from a modified NaHTe solution with a good purity degree and uniformity, just dripping the NaHTe: $\mathrm{NH}_{3}$ solution onto a substrate under ambient conditions. Besides, this synthesis

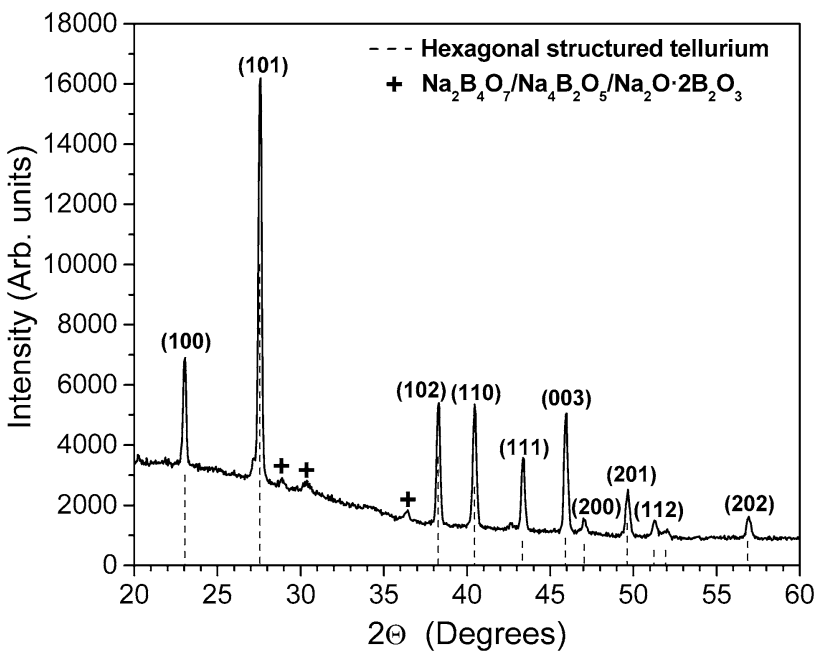

Fig. 7 X-ray diffraction pattern of a nanostructured tellurium deposition, realized by the dropping of NaHTe:ammonia solution

rich in ammonia created an environment favorable to protect the telluride ions of the presence of environmental oxygen, factor which favors the formation of oxides and tellurates.

$\mathrm{X}$-ray diffraction analysis indicated that the diffraction peaks showed in Fig. 7 correspond to the hexagonal phase of tellurium [10] with a preferred orientation on the (101) direction, corroborating the results obtained by electron diffraction in section "X-ray diffraction analysis". Although the phase of borates was not removed, their presence in the diffraction pattern has been significantly reduced.

\section{Conclusions}

We have prepared a uniform and highly adherent tellurium deposition by a relatively simple process that does not require strict inert atmosphere, starting from a highly reactive compound with oxygen, such as NaHTe and without needing any organic stabilizer. Synthesis of tellurium powder with $\mathrm{NaBH}_{4}$ in aqueous $\mathrm{NH}_{4} \mathrm{OH}$ solution resulted in a purple hue darker solution, with higher viscosity compared to a NaHTe standard solution, but highly stable under laboratory conditions. According to TEM analysis, the solution contains various types of tellurium nanostructures, these nanostructures are nearly spherical nanoparticles, nanorods and structures of type "Y", nanostructures traditionally obtained by chemical vapor techniques.

Acknowledgments The authors thank Consejo Nacional de Ciencia y Tecnología (CONACyT-México) by its sponsorship, Álvaro Guzmán Campuzano by his technical assistance, and M.S. Adolfo Tavira Fuentes by the XRD measurements. 
Open Access This article is distributed under the terms of the Creative Commons Attribution 4.0 International License (http:// creativecommons.org/licenses/by/4.0/), which permits unrestricted use, distribution, and reproduction in any medium, provided you give appropriate credit to the original author(s) and the source, provide a link to the Creative Commons license, and indicate if changes were made.

\section{References}

Bao H, Gong Y, Li Z, Gao M (2004) Enhancement effect of illumination on the photoluminescence of water-soluble CdTe nanocrystals: toward highly fluorescent $\mathrm{CdTe} / \mathrm{CdS}$ core-shell structure. Chem Mater 16:3853-3859

Cooper ED (1974) Tellurium. Van Nostrand Reinhold Co., New York

Fujiwara S, Ike TS, Okada K, Aoki M, Kambe N, Sonoda N (1992) A marvelous catalysis of tellurium in the formation of isothiocyanates from isocyanides and sulfur. Tetrahedron Lett 33:7021-7024
Furuta N, Ohashi Y, Itinose H, Igarashi Y (1975) Kinetics of vaporgrown tellurium whiskers. Jpn J Appl Phys 14:929-934

Gautam Ujjal K, Rao CNR (2004) Controlled synthesis of crystalline tellurium nanorods, nanowires, nanobelts and related structures by a self-seeding solution process. J Mater Chem 14:2530-2535

Gerlach E, Grosse P (1979) The physics of selenium and tellurium. Springer, Berlin

Gu Z, Zou L, Fang Z, Zhou W, Zhong X (2008) One-pot synthesis of highly luminescent $\mathrm{CdTe} / \mathrm{CdS}$ core/shell nanocrystals in aqueous phase. Nanotechnology 19:135604

Rabadanov MKh, Verin IA, Ivanov YuM, Simonov VI (2001) JCPDS International Centre for Difraction Data calculated from ICSD using POWD-12++. Kristallografiya 46:703

Ufimtsev VB, Osvensky VB, Bublik VT, Sagalova TB, Jouravlev OE (1997) Structure, homogeneity and properties of thermoelectric materials based on ternary solid solutions of bismuth and antimony chalcogenides. Adv Perform Mater 4:189-197

Zheng R, Cheng W, Wang E, Dong S (2004) Synthesis of tellurium nanorods via spontaneous oxidation of NaHTe at room temperature. Chem Phys Lett 395:302-305 